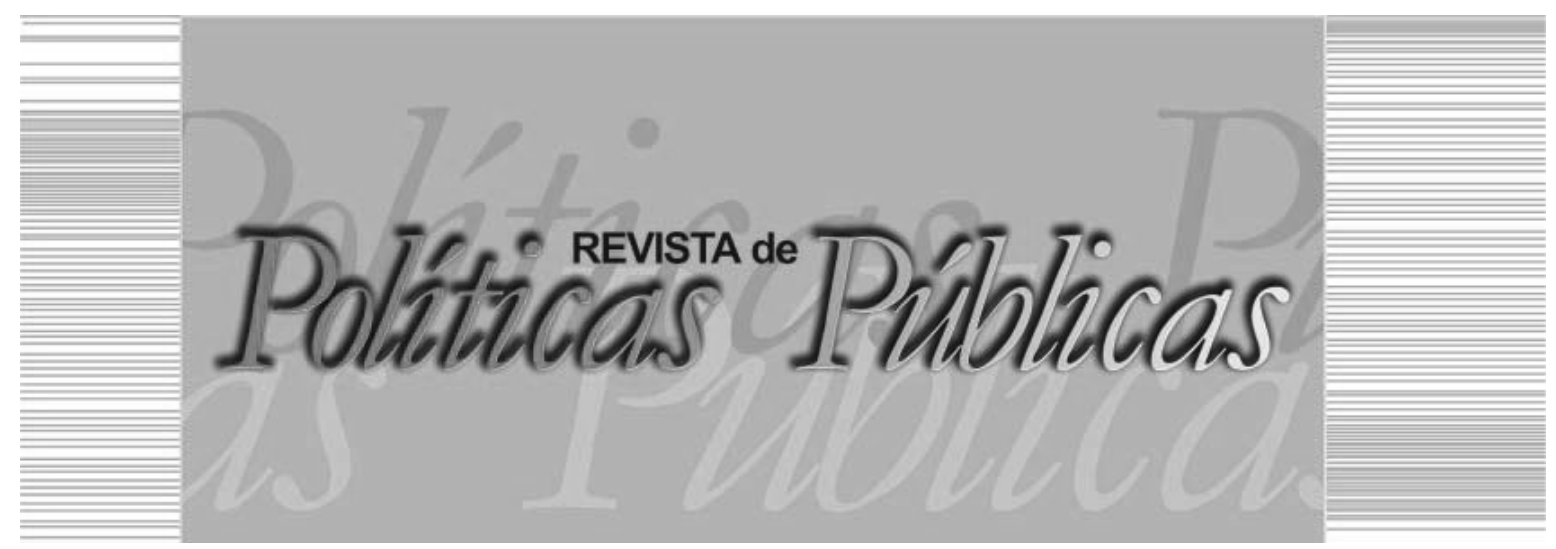

\title{
A INDÚSTRIA PARANAENSE E O PROGRAMA PARANÁ COMPETITIVO: descentralização e o desenvolvimento do setor ${ }^{1}$
}

\author{
Augusta Pelinski Raiher ${ }^{l}$ \\ Universidade Estadual de Ponta Grossa (UEPG) \\ Alex Sander Souza do Carmo ${ }^{2}$ \\ Universidade Estadual de Ponta Grossa (UEPG) \\ Hermes Yukio Higachi ${ }^{3}$ \\ Universidade Estadual de Ponta Grossa (UEPG) \\ Jorge Eduardo Wekerlin 4 \\ Instituto de Ciências Sociais do Paraná \\ Universidade Estadual de Ponta Grossa (UEPG)
}

\section{Resumo}

O objetivo deste trabalho é analisar a descentralização e o desenvolvimento da indústria entre os municípios paranaenses, investigando a importância do

\footnotetext{
Economista, Doutora em Economia pela Universidade Federal do Rio Grande do Sul (UFRGS), Professora do Programa de Pós-Graduação em Economia, do Programa de PósGraduação em Ciências Sociais e do Curso de Economia da Universidade Estadual de Ponta Grossa (UEPG). E-mail: apelinski@gmail.com

2 Economista, Doutor em Economia pela Universidade Federal do Paraná (UFPR), Professor do Programa de Pós-Graduação em Economia e do Curso de Economia da UEPG. E-mail: acarmo@uepg.br

3 Economista, Doutor em Economia pela Universidade Estadual de Campinas (UNICAMP), Professor do Programa de Pós-Graduação em Economia e do Curso de Economia da UEPG. E-mail: hhigachi@gmail.com

${ }^{4}$ Economista, Doutor em Engenharia Florestal pela UFPR, Professor do Instituto de Ciências Sociais do Paraná e do Curso de Economia da UEPG. E-mail: jew@gmail.com / Universidade Estadual de Ponta Grossa - UEPG: Campus Uvaranas - Av. General Carlos Cavalcanti, 4748 - Curitiba, PR. CEP: 84030-900; Instituto de Ciências Sociais do Paraná: Rua General Carneiro 216 - Térreo - Curitiba, PR. CEP: 80060-150
} 
Augusta Pelinski Raiher | Alex Sander Souza do Carmo

Hermes Yukio Higachi | Jorge Eduardo Wekerlin

Programa Paraná Competitivo neste processo. Para isso, construiu-se um índice de desenvolvimento da indústria (IDI) e, por meio da econometria espacial, analisou-se o efeito do Programa Paraná Competitivo na descentralização e no desenvolvimento da indústria entre os municípios paranaenses. Verificou-se um processo de descentralização da indústria ao longo do estado, com o melhoramento da sua produtividade, apresentando um efeito positivo e significativo do Programa tanto no processo de descentralização como também no desenvolvimento do setor.

Palavras-chave: Indústria, descentralização, produtividade, Programa Paraná Competitivo.

\title{
THE PARANÁ INDUSTRY AND THE PARANÁ
}

COMPETITIVE PROGRAM: decentralization and development of the sector

\begin{abstract}
The objective of this study is to analyze the decentralization and the development of the industry among the municipal districts, investigating the importance of Parana competitive program in this process. For this, it was built up an industry development index (IDI) and through spatial econometrics, it was analyzed the effect of Parana Competitive Program in the decentralization and development of the industry among the municipal districts. It was observed an industry decentralization process throughout the state, with the improvement of productivity by presenting a positive and significant effect of the program both in the decentralization process as well as the development of the sector.

Key words: Industry, decentralization, productivity, Parana Competitive Program.
\end{abstract}

\section{INTRODUÇÃO}

A distribuição espacial das atividades produtivas apresenta-se como decisiva no processo do desenvolvimento econômico de uma região. Quando uma empresa se instala em determinado ponto do espaço, feedbacks positivos podem ser gerados, reforçando as externalidades locais, atraindo novos empreendimentos. (KRUGMAN, 1991). Esse processo positivo conduz a formação e ampliação dos aglomerados, decorrentes especialmente da concentração de mão de obra, da presença de infraestrutura, da concentração do setor de serviço, e dos próprios spillovers tecnológicos.

Assim, o ponto onde inicialmente se instalou uma unidade produtiva tende a se beneficiar, gerando empregos diretos no setor 
A INDÚSTRIA PARANAENSE E O PROGRAMA PARANÁ COMPETITIVO:

descentralização e o desenvolvimento do setor

induzido, como também em outros segmentos encadeados à indústria entrante. Ademais, processa-se um efeito renda, induzindo a outras atividades locais, gerando indiretamente a fomentação da economia.

Esses efeitos podem transcender os limites territoriais, beneficiando as regiões vizinhas, por meio da absorção de mão de obra, da compra de matérias-primas, bem como por meio da instalação de empresas satélites neste envoltório. Ou seja, a aglomeração inicial em um ponto do espaço pode gerar benefícios para o seu entorno, formando uma cadeia produtiva importante no que tange à produtividade, emprego e renda.

A expectativa é que outros espaços regionais se beneficiem, ex post, dessas economias externas, desenvolvendo seus parques produtivos e elevando a produtividade da indústria. Saboia e Kubrusly (2008) inferem a importância dessa descentralização no desenvolvimento industrial especialmente pelos transbordamentos que as indústrias entrantes e/ou nascentes trazem para a região, como, por exemplo, mão de obra qualificada, spillovers tecnológicos, otimização dos custos pela proximidade com seus fornecedores, infraestrutura instalada, dentre outros fatores.

No Brasil, a distribuição da atividade produtiva foi sempre desigual, com uma concentração que privilegiou especialmente o Sudeste do país. No auge da concentração do setor, anos de 1970, São Paulo respondia por $58 \%$ da produção nacional. Nas décadas seguintes, um processo de descentralização industrial começou a ser implementado, tendendo a uma integração produtiva inter-regional.

Em um primeiro momento, o processo de desconcentração privilegiou o interior do próprio estado de São Paulo, dirigindo-se para outras regiões nos anos seguintes, com destaque para o Sul do país. No caso do Paraná, vários fatores foram decisivos para que as indústrias buscassem se instalar na região. Bragueto (2007) cita, dentre outros: a infraestrutura básica, como rede ferroviária moderna, ferrovias, porto marítimo e energia elétrica; a existência de mecanismos institucionais de apoio à indústria, centrados no Banco de Desenvolvimento do Estado do Paraná (BADEP), e uma série de outros órgãos públicos voltados à atração de indústrias, rede ampla de incentivos e subsídios municipais, estaduais e federais, e; o forte desempenho do setor agrícola, com uma verticalização agrícola-agroindustrial. Ademais, a proximidade com o Mercosul foi crucial neste processo. Essas transformações colocaram o Paraná em quarto 
Augusta Pelinski Raiher | Alex Sander Souza do Carmo

Hermes Yukio Higachi $\mid$ Jorge Eduardo Wekerlin

lugar no ranking da industrialização nacional, responsável por 8,4\% do PIB do setor em 2014. (INSTITUTO DE PESQUISA ECONÔMICA APLICADA, [20--?]; INSTITUTO BRASILEIRO DE GEOGRAFIA E ESTATISTICA, 2014).

É importante destacar que boa parte de toda industrialização efetuada na década de 1990 se deu na Região Metropolitana de Curitiba. Tal região detinha, no início dos anos de 2000, em torno de 50\% de todo valor adicionado da indústria, demonstrando o caráter concentrador da atividade produtiva existente no Paraná. (INSTITUTO PARANAENSE DE DESENVOLVIMENTO ECONÔMICO E SOCIAL, 2003). Ou seja, o estado se beneficiou com a descentralização da indústria que ocorreu no país, mas não necessariamente todos os espaços paranaenses participaram desse processo.

Nos anos de 2000, uma nova política industrial foi implementada no Paraná, o que potencialmente afetou a sua dinâmica produtiva. Trata-se do Programa Paraná Competitivo, criado em 2011, cujo principal objetivo consiste na atração de novos investimentos, promovendo a descentralização regional do setor. Tem como mecanismo de atração o parcelamento do Imposto sobre Circulação de Mercadorias e Serviços (ICMS) incremental, além de propor medidas para o melhoramento da infraestrutura, do comércio exterior, da capacitação profissional, dentre outras. No período entre fevereiro de 2011 e dezembro de 2014, o programa de industrialização contabilizou a atração de mais de R $\$ 35$ bilhões em investimentos industriais privados, nacionais e multinacionais, distribuídos em vários municípios da Região Metropolitana de Curitiba e do interior do Estado do Paraná.

Enfim, a atividade produtiva do Paraná vem sendo afetada por diferentes fatores, tanto internos como também externos. Analisar a sua localização e o seu desenvolvimento se torna crucial para a promoção do crescimento econômico. Se forem considerados os argumentos teóricos de que a localização da indústria gera benefícios posteriores para todo o seu envoltório (HIRSCHMAN, 1961; KRUGMAN, 1991), fomentando o desenvolvimento da atividade num espaço maior, então a distribuição industrial que vem se dando nos anos de 2000, por conta do Programa Paraná Competitivo, pode estar promovendo efeitos de transbordamento ao longo do espaço paranaense. 
Assim, considerando o contexto acima exposto, o objetivo principal do presente trabalho é analisar se o programa de industrialização Paraná Competitivo, implementado em 2011, contribuiu para o processo de descentralização e de desenvolvimento da indústria (em termos de produtividade) nos municípios paranaenses.

Para tanto, além dessa introdução, o artigo está composto por mais quatro seções. Na segunda, apresentam-se inferências teóricas acerca das aglomerações produtivas; os elementos teóricos e metodológicos constituem a seção seguinte. Os efeitos do programa Paraná Competitivo na descentralização e no desenvolvimento da indústria paranaense são analisados na quarta seção. Por fim, a quinta seção reporta-se às considerações finais.

\section{AGLOMERAÇÕES PRODUTIVAS}

A respeito da origem das aglomerações produtivas, a literatura aponta que estas podem ocorrer de forma espontânea, sendo influenciadas pelas condições físicas da região (como clima, produtividade do solo, etc.), pela abundância de insumos (como a presença de mão de obra qualificada, etc.), ou devido às questões logísticas (como fácil acesso por terra e/ou mar). Todavia, as aglomerações também podem ser induzidas por meio de políticas públicas de desenvolvimento regional (como isenção de impostos), que acabam incentivando as firmas a se instalarem em determinadas localidades.

Destaca-se que a investigação das aglomerações industriais não é algo relativamente novo na literatura, pois um dos primeiros autores a abordar o referido tema foi Alfred Marshall, em 1890. A partir da configuração industrial da Inglaterra do século XIX, Marshall (1890) buscou compreender quais são os principais fatores responsáveis pela aglomeração industrial, e quais as vantagens competitivas que a aglomeração traz às firmas ali localizadas. Nesse sentido, o autor identificou que a concentração de conhecimento, habilidades e know how poderia criar um ambiente propício ao desenvolvimento industrial.

Para Marshall (1890) os principais fatores que originam as aglomerações industriais são as economias de escala, as quais podem ser internas ou externas às firmas. As economias de escala são consideradas internas às firmas quando são oriundas da estrutura de custo das firmas, em geral grandes, e que, por meio da organização da produção, conseguem uma vantagem de custos sobre as firmas 
pequenas. Já as economias de escala externas às firmas, mas internas às indústrias, são oriundas das vantagens advindas da aglomeração produtiva em determinada região. Para Marshall (1890) três elementos contribuem para isso: i) um mercado de trabalho com mão de obra qualificada; ii) a disponibilidade de serviços e fornecedores especializados; iii) o efeito spillover de tecnologia e conhecimento; esse conjunto de fatores ficou conhecido na literatura como tríade marshalliana.

Na visão de Schmitz (1997), tanto as economias externas marshallianas quanto as economias de urbanização fornecem uma visão limitada dos benefícios das aglomerações. Para esse autor, a principal vantagem da aglomeração está ligada à eficiência coletiva da região. Entende-se por eficiência coletiva a capacidade dos agentes utilizarem a seu favor as economias externas, como também as ações planejadas. Nesse caso, as economias externas oriundas de ações não planejadas, que resultam em ganhos de eficiência para as firmas devido à proximidade geográfica (à la tríade Marshalliana); como, por exemplo, a presença de mão de obra qualificada. Por outro lado, as ações planejadas são aquelas medidas conjuntas implementadas pelas empresas, ou por instituições locais, objetivando a redução conjunta de custos; como, por exemplo, o compartilhamento de máquinas e equipamentos, ações de marketing, etc.

Krugman (1991) também critica a simplificação da economia tradicional, a qual dá pouca ênfase à localização dos fatores de produção no espaço, principalmente nas teorias de comércio internacional. Nesse caso, o autor destaca que uma forma de compreender o funcionamento da economia internacional é analisar as particularidades de cada nação. Com isso, busca-se identificar as concentrações econômicas no espaço geográfico, em que essa concentração refletirá a influência de algum tipo de rendimento crescente de escala.

Em Krugman (1991), a concentração espacial da indústria é resultado de dois tipos de forças, as quais são classificadas em: de aglomeração (centrípeta) e de dispersão (centrífuga). A força de aglomeração está em linha com a tríade marshalliana e a força de dispersão oriunda da imobilidade da mão-de-obra, do custo de transporte e da deterioração do meio-ambiente. Ademais, é importante mencionar que o avanço das tecnologias de telecomunicação e dos transportes reduziram, respectivamente, os custos de comunicação e de transporte, resultando em desincentivos à aglomeração. 
A INDÚSTRIA PARANAENSE E O PROGRAMA PARANÁ COMPETITIVO:

descentralização e o desenvolvimento do setor

Já as forças centrípetas da concentração resumem-se em: ligações para frente (forward linkages) e para trás (backward linkages) das atividades produtivas (fatores/serviços produtivos), mercados de trabalho densos e especializados, spillovers de conhecimento. Assim, devido à interação desses fatores, as aglomerações produtivas se tornam espaços privilegiados, com uma capacidade superior de gerar mais riqueza do que as atividades dispersas, essencialmente por apresentarem mais oportunidades de ampliar as economias de escala.

Pormenorizando os fatores que levam à concentração da atividade econômica, no caso do mercado de trabalho, sob o ponto de vista do empregado, estar situado em um aglomerado produtivo diminui o risco de ficar desempregado, devido a existência de um grande número de firmas localizadas na região. Sob o prisma do empresário, caso se opte por majorar a produção, o mesmo não terá muitas dificuldades para encontrar mão de obra qualificada, devido a mesma estar concentrada no espaço. Assim, nas regiões em que as atividades econômicas são concentradas, as flutuações no mercado de trabalho tendem a ser suavizadas, tanto em termos de oportunidade de emprego para o trabalhador como também de oscilação salarial para o empresário.

A segunda razão que leva à concentração industrial está na oferta de serviços fatores intermediários. Krugman (1991) advoga que uma indústria concentrada possibilita a existência de um maior número de provedores locais especializados, os quais serão mais eficientes e mais diversificados, aproveitando os benefícios das economias de escala por atuarem em um mercado mais abrangente. Além disso, os fornecedores intermediários elevam as suas chances de aumentar a sua clientela, tendo em vista a possibilidade de fornecerem bens e serviços para as firmas que irão se instalar no espaço.

Por último, o spillover de conhecimento advém da proximidade locacional das empresas, possibilitando um grande fluxo de conhecimento científico e tecnológico dentro do espaço geográfico. Nesse sentido, Scitovsky (1954) já identificara que os spillovers de conhecimento resultam das interações realizadas fora do mercado, mas são realizadas por meio de processos que afetam diretamente as funções de produção das firmas, ressaltando-se que os fluxos de conhecimento no interior do espaço geográfico são invisíveis e de difícil mensuração. 
Um ponto importante a ser aqui considerado, refere-se ao tipo de atividade econômica que é mais propensa a ser concentrada espacialmente. Frequentemente, devido à notoriedade alcançada pelos parques tecnológicos dos Estados Unidos, é inevitável fazer uma associação entre concentração industrial e a indústria de alta tecnologia. No entanto, restringir a concentração industrial a esse tipo de indústria é uma visão equivocada desse processo. Krugman (1991) aponta que muitas das industriais concentradas nos Estados Unidos não necessariamente pertenciam ao setor de alta tecnologia, indicando a existência de outras forças, além da tecnologia, como fomentadoras da concentração.

Corroborando a visão de Krugman (1991), em estudo para o Brasil, Saboia (2000) identificou um grande número de aglomerações industriais espalhadas ao longo do território nacional; em 16 dos 27 estados brasileiros. Ademais, identificou-se que as concentrações industriais são bastante especializadas, tendo em vista que na maior parte dos casos o emprego industrial se concentrou em um único setor. Já em termos setoriais, as aglomerações concentram, principalmente, atividades de setores tradicionais da indústria, como alimentícia, madeireira, têxtil, entre outras.

\section{METODOLOGIA}

A partir de 2011, uma nova política industrial foi implementada no Paraná, denominada de Programa Paraná Competitivo, cuja ação versa na descentralização e fomentação da indústria paranaense. Na presença de tal política, conjuntamente com o processo natural de descentralização que vem se operando ao longo do país, se questiona sobre os ganhos que os municípios paranaenses obtiveram em termos de desenvolvimento da indústria nos últimos anos.

Nesse contexto, inicialmente analisou-se a distribuição do emprego industrial ao longo do estado em 2011 e 2014, mensurando o impacto do Programa Paraná Competitivo na formação dos aglomerados de emprego industrial do Paraná e no processo de descentralização dos postos de trabalho industriais. Posteriormente, construiu-se um Índice de Desenvolvimento da Indústria (IDI), investigando novamente o efeito do Programa Paraná Competitivo na elevação da produtividade da indústria paranaense. 
A INDÚSTRIA PARANAENSE E O PROGRAMA PARANÁ COMPETITIVO:

descentralização e o desenvolvimento do setor

\section{1 Índice de Desenvolvimento da Indústria: sua Construção e}

Análise Exploratória dos Dados Espaciais

$\mathrm{Na}$ análise do desenvolvimento do setor secundário, mensurou-se IDI (1), considerando três indicadores: escolaridade média dos trabalhadores da indústria, salários médios ${ }^{2}$ do setor secundário e percentual de ocupações técnicas e científicas da indústria, conforme metodologia apresentada por Saboia e Kubrusly (2008), ressaltando que todos os dados foram coletados da Relação Anual de Informações Sociais (RAIS) e referem-se ao emprego formal.

$$
\mathrm{IDI}_{\mathrm{i}, \mathrm{t}}=\emptyset_{1}\left(\mathrm{ESC}_{\mathrm{i}, \mathrm{t}}\right)+\emptyset_{2}\left(\mathrm{SAL}_{\mathrm{i}, \mathrm{t}}\right)+\emptyset_{3}\left(\mathrm{OT}_{\mathrm{i}, \mathrm{t}}\right)
$$

Em que: IDI refere-se ao índice de desenvolvimento da indústria; ESC é a escolaridade média da indústria; SAL refere-se ao salário médio; OT é o percentual de ocupações técnicas e científicas; i é o município; t é o tempo; $\phi$ refere-se ao peso.

O peso ( $\emptyset$ ) de cada um dos indicadores de (1) foi obtido por meio da análise de componentes principais. Essa metodologia indica o percentual da variância da dispersão total de uma nuvem de pontos (atributos do desenvolvimento) que é caracterizado por cada um dos indicadores de (1), através da matriz de correlação das variáveis.

Seguindo a metodologia utilizada por Crocco e outros (2006), na construção dos pesos de (1) não foram utilizados os valores dos componentes em si, mas os resultados anteriores à análise de componentes principais, com as seguintes etapas:

i) Obtenção dos autovalores da matriz de correlação, por meio da análise do componente principal (ACP). Em cada um deles tem-se a explicação na variância, destacando que a soma dos betas corresponde à variância total dos componentes e, dessa forma, à variância total dos indicadores selecionados.

ii) Recálculo dos autovalores da matriz de correlação, buscando encontrar a participação relativa de cada um dos elementos em cada um dos componentes. Primeiramente cada autovalor é adotado em módulo e dividido pelo somatório dos autovalores absolutos de seu componente, obtendo sua participação no componente correspondente. 
Augusta Pelinski Raiher | Alex Sander Souza do Carmo

Hermes Yukio Higachi | Jorge Eduardo Wekerlin

iii) A construção dos pesos é dada por meio da multiplicação da participação relativa dos indicadores nos componentes com a variação caracterizada pelo componente. A soma fornece o peso de cada indicador.

A soma dos pesos $\phi_{1}+\phi_{2}+\phi_{3}$ é igual a um e, assim, cria-se uma combinação linear dos indicadores propriamente padronizados. Esses pesos, então, são aplicados em (1), auferindo o IDI. Os pesos obtidos encontram-se no APÊNDICE B.

De posse do índice, efetuou-se a análise exploratória dos dados espaciais (AEDE), com o intuito de se descrever a distribuição e os padrões de associação espacial do IDI entre os municípios do Paraná.

Para se implementar a AEDE é necessária a adoção de uma matriz de ponderação espacial (W). Conforme Almeida (2012), essa é uma matriz quadrada de ordem n por n, cujos elementos denotam o grau de conexão espacial entre os municípios em análise, seguindo algum critério de proximidade.

O critério de proximidade baseia-se na contiguidade (com convenção do tipo torre, rainha e do vizinho mais próximo). Na implementação da AEDE foi utilizado o teste de autocorrelação espacial global (via estatística I de Moran (2)), a qual permite identificar se a distribuição espacial de uma determinada variável ocorre de forma aleatória ou não. Caso a distribuição espacial for considerada aleatória, então o comportamento dessa variável na região i não é influenciado pelo comportamento dessa mesma variável na região j.

Em que: $\mathrm{n}$ denota o número de municípios; $\mathrm{z}$ é o valor do IDI (padronizado); Wz representa os valores médios do IDI (padronizados nos vizinhos), e definidos conforme a matriz de ponderação espacial adotada (W); $\mathrm{S}_{0}$ é o somatório de todos os elementos da matriz de ponderação espacial (W).

A hipótese nula a ser testada é a de que a distribuição espacial do IDI é aleatória.

Também se mensurou a autocorrelação espacial global num contexto bivariado (3), procurando descobrir se os valores de uma variável observada (IDI) em um determinado município têm uma relação sistemática com os valores de uma outra variável observada (presença de investimentos do Paraná Competitivo) nos municípios vizinhos. 


$$
\mathrm{I}^{\mathrm{yx}}=\frac{\mathrm{n}}{\sum_{\mathrm{i}} \sum_{\mathrm{j}} \mathrm{w}_{\mathrm{ij}}} \frac{\sum_{\mathrm{i}} \sum_{\mathrm{j}}\left(\mathrm{x}_{\mathrm{i}}-\overline{\mathrm{x}}\right) \mathrm{w}_{\mathrm{ij}}\left(\mathrm{y}_{\mathrm{i}}-\overline{\mathrm{y}}\right)}{\sum_{\mathrm{i}}\left(\mathrm{x}_{\mathrm{i}}-\overline{\mathrm{x}}\right)^{2}}
$$

\subsection{Modelos Empíricos e Estratégia de Estimação dos Parâmetros}

O principal objetivo deste artigo é testar o efeito do Programa Paraná Competitivo no emprego e no IDI dos municípios paranaenses, através da econometria espacial. As primeiras estimativas analisaram o efeito do Programa no nível de emprego e na sua variação. Para isso, uma dummy representativa dos investimentos do Paraná Competitivo foi criada, com valor um para os municípios que receberam investimentos do Programa entre 2011 e 2014 e zero caso contrário. Além dessa variável explicativa, se incluiu como variáveis de controle uma proxy para o caráter Path Dependence (dependência da trajetória) do processo de industrialização dos municípios do Estado do Paraná, referindo-se à média de empregos da indústria entre 2000 e 2010 (período anterior ao Programa Paraná Competitivo), e outra proxy para aglomerações especializadas na alta e média alta tecnologia.

Para esta última, foi representada por uma dummy, com valor igual a um para os municípios que apresentaram um percentual de emprego da indústria da alta e média alta tecnologia (classificação de FURTADO; CARVALHO, 2005) igual ou superior a $50 \%$ do total de emprego existente em 2014, e zero caso contrário. Optou-se por captar as aglomerações especializadas da alta e da média alta tecnologia por, teoricamente, deterem uma produtividade mais elevada que as demais estruturas produtivas, influenciando principalmente $o$ desenvolvimento do setor.

Isto posto, o primeiro modelo estimado referiu-se ao efeito dessas variáveis supracitadas sobre o nível de emprego industrial dos municípios paranaenses (4).

$$
\mathrm{EMP}_{\mathrm{i}}^{14}=\beta_{0}+\beta_{1} \mathrm{EMP}_{\mathrm{i}}^{(00 / 10)}+\beta_{2} \mathrm{PRC}_{\mathrm{i}}+\beta_{3} \mathrm{TEC}_{\mathrm{i}}+\mathrm{u}_{\mathrm{i}}
$$

Em que: $\mathrm{EMP}_{\mathrm{i}}^{14} \mathrm{EMP}_{\mathrm{i}}^{14}$ é o número de postos de trabalho da indústria no ano de 2014; $\mathrm{Emp}^{(10 / 14)} \mathrm{Emp}^{(10 / 14)}$ é a média do emprego industrial no período de 2000-2010 (proxy para o Path Dependence industrial); $\mathrm{PRC}_{\mathrm{i}} \mathrm{PRC}_{\mathrm{i}}$ refere-se à dummy para a presença de inves- 
timento do programa Paraná Competitivo; $\mathrm{TEC}_{\mathrm{i}} \mathrm{TEC}_{\mathrm{i}}$ refere-se à aglomeração especializada na alta e média alta tecnologia; e $u_{i} u_{i}$ é o termo de erro aleatório.

Já o segundo modelo especificado (5) buscou identificar o efeito do Programa Paraná Competitivo na descentralização da atividade produtiva, avaliando seu impacto na variação do emprego industrial entre 2011 e $2014\left(\Delta \mathrm{EMP}^{(11 / 14)} \Delta \mathrm{EMP}_{\mathrm{i}}^{(11 / 14)}\right)$. $\Delta \operatorname{EMP}_{i}^{(11 / 14)}=\beta_{0}+\beta_{1} \operatorname{EMP}_{i}^{(00 / 10)^{1}}+\beta_{2} \mathrm{PRC}_{\mathrm{i}}+\beta_{3} \mathrm{TEC}_{\mathrm{i}}+\mathrm{u}_{\mathrm{i}}$

Por fim, a terceira estimativa (6) busca analisar o efeito do Programa Paraná Competitivo no IDI. A suposição é de ao fomentar a industrialização, elevando a geração de empregos ao longo dos municípios paranaenses, o Paraná Competitivo aumentou a produtividade do setor, contribuindo para o seu desenvolvimento.

$$
\text { IDI }_{i}=\beta_{0}+\beta_{1} \text { EMP }_{i}^{(00 / 10)}+\beta_{2} \text { PRC }_{i}+\beta_{3} \text { TEC }_{i}+u_{i}
$$

Todas as estimativas [(4), (5) e (6)] foram realizadas por meio da econometria espacial, dada a existência de dependência espacial, conforme apresentado no APÊNDICE A. Nesta metodologia, o primeiro passo é a decisão sobre o melhor modelo espacial: Modelo de defasagem espacial (SAR) ou Modelo de erro autorregressivo espacial (SEM). Para detectar a autocorrelação espacial e definir o modelo espacial mais apropriado, consideram-se os testes focados do tipo Multiplicador de Lagrange (ML).

Considerando os resultados do ML $\rho$ e ML $\lambda$ (Tabela 1 e 3), o modelo econométrico mais indicado para (4) e (6) refere-se ao SAR, e para (5) é o SEM.

No caso do SAR, ele pode ser expresso por (7).

$$
\mathrm{y}=\rho \mathrm{Wy}+\mathrm{X} \beta+\varepsilon
$$

Em que y é a variável dependente; $\rho \rho$ é o coeficiente autorregressivo espacial; WyWy é um vetor nx 1 de defasagens espaciais para a variável dependente; $X$ é a matriz das variáveis explicativas; $\beta \beta$ é um vetor de parâmetros e é o termo erro.

Modelos do tipo (7) indicam que "[...] uma mudança na variável explicativa numa região afetará não apenas a própria região pelo efeito direto, mas pode afetar o valor da variável dependente 
A INDÚSTRIA PARANAENSE E O PROGRAMA PARANÁ COMPETITIVO:

descentralização e o desenvolvimento do setor

em todas as regiões por meio dos efeitos indiretos." (ALMEIDA, 2012, p. 157).

O modelo SEM é expresso por (8):

Em que o parâmetro $\lambda$ é o erro autorregressivo espacial que acompanha a defasagem $\mathrm{W} \xi$. Nesse modelo a dependência espacial em (8.1) se revela no termo de erro, enfatizando que os erros relacionados com qualquer observação são uma média dos erros nas regiões do envoltório, acrescentados de um componente aleatório.

Todas as estimativas que apresentaram problemas econométricos (heterocedasticidade ou normalidade) foram reestimadas, com a correção dos referidos problemas. Para controlar a heterocedasticidade utilizou-se a correção de heterocedasticidade pela matriz de White. No caso da ausência de normalidade nos erros, usou-se o método de momentos generalizados, pois prescinde da hipótese da normalidade dos erros. Todas as estimativas apresentaram resíduos sem dependência espacial (como reportado no APÊNDICE A).

\section{ANÁLISE DOS RESULTADOS}

O processo de desconcentração regional da indústria brasileira, promovido a partir dos anos de 1970, tornou-se importante por conduzir o dinamismo econômico para outros pontos do país. Saboia e Kubrusly (2008) argumentam que essa descentralização não beneficiou apenas as capitais brasileiras, ocorrendo um movimento importante de interiorização desse processo.

No caso do Paraná, 44\% do emprego industrial estavam alocados na capital em 1984, passando para 18\% em 2010 e 16\% em 2014. Essa descentralização é reflexo do elevado crescimento do emprego industrial que se teve ao longo do estado: enquanto Curitiba praticamente permaneceu com o mesmo montante de emprego industrial entre 2010 e 2014, os demais municípios em conjunto incrementaram seus postos de trabalho em $8,5 \%$.

A decomposição da geração de empregos entre os municípios do estado (Figura 1c) demonstra essa descentralização em favor do interior paranaense, elevando o número de postos de trabalho da indústria em $79 \%$ dos municípios. Destarte, embora o emprego industrial apresente praticamente a mesma distribuição espacial ao longo dos anos (Figura 1a e 1b), privilegiando especialmente a região me- 
tropolitana de Curitiba e o envoltório do estado, seu crescimento se deu ao longo de todo o Paraná (Figura 1c).

Figura 1 - Emprego industrial em 2010 (a), em 2014 (b), taxa de crescimento do emprego industrial entre 2010 e 2014 (c) e Investimentos do Paraná

Competitivo entre 2011 e 2014 (d) - municípios do Paraná

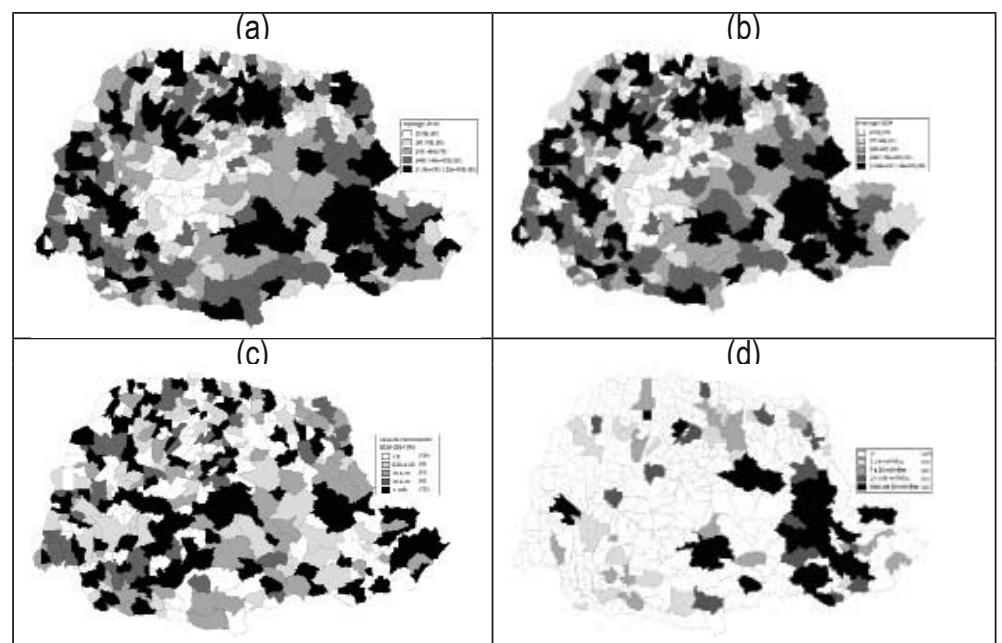

Fonte: Elaborada pelos autores, conforme informações: BRASIL. Ministério do Trabalho. Relação Anual de Informações Sociais: acesso ao sistema. Brasília, DF, [20--?]. Disponível em:<http:// bi.mte.gov.br/bgcaged/login.php>. Acesso: 1 maio 2016.

Em parte, o crescimento da atividade produtiva ao longo do Paraná pode ser resultado da implementação do Programa Paraná Competitivo, criado a partir de 2011, com o objetivo de atrair novos investimentos, promovendo a descentralização regional. Na Figura $1 \mathrm{~d}$ tem-se a distribuição destes recursos, vislumbrando certa associação espacial entre a localização destes valores e o ritmo de crescimento do emprego industrial. Ademais, o Gráfico 1 corrobora tal percepção, evidenciando que o crescimento do emprego industrial nos municípios que receberam recursos do Programa Paraná Competitivo é levemente superior ao crescimento dos demais municípios do estado, apresentando também uma superioridade em relação aos demais municípios brasileiros. 
A INDÚSTRIA PARANAENSE E O PROGRAMA PARANA COMPETITIVO:

descentralização e o desenvolvimento do setor

Gráfico 1 - Taxa de crescimento do emprego industrial -

Municípios que receberam investimento do Paraná Competitivo (Pr competitivo), Paraná e Brasil - 2010 a 2014 (\%)

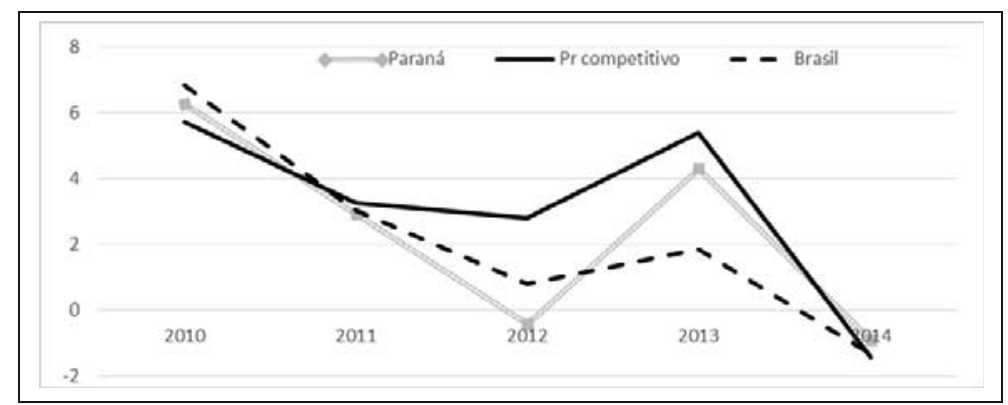

Fonte: Elaborada pelos autores, com dados originais da RAIS.

Corroborando esses resultados, têm-se as estimativas na Tabela 1. Nas três primeiras regressões testou-se o efeito do Programa Paraná Competitivo sobre o emprego industrial em 2014. Ressalta-se que a utilização da econometria espacial foi necessária dada a dependência espacial existente, conforme anexo $\mathrm{A}^{3}$. Ademais, o modelo mais apropriado, segundo os testes do tipo focado (Tabela 1), refere-se ao modelo SAR.

Os resultados apontam para um efeito positivo e significativo do Programa Paraná Competitivo sobre o emprego industrial, inferindo que aqueles municípios que receberam recursos do Paraná Competitivo entre 2011 e 2014 tiveram, na média, um montante de emprego superior aos demais municípios do estado em 2014.

No caso da Proxy, utilizada para a variável Path Dependence industrial $\left(\mathrm{EMP}_{\mathrm{i}}^{(00 / 10)} \mathrm{EMP}_{\mathrm{i}}^{(00 / 10)}\right)$, também se mostrou positiva e significativa, ou seja, quanto maior é o aglomerado de empregos da indústria existente ex ante, maior tende a ser o aglomerado industrial resultante ex post, reflexo de toda a trajetória passada que o município percorreu.

A dummy utilizada para captar a aglomeração especializada na alta e média alta tecnologia $\left(\mathrm{TEC}_{\mathrm{i}}\right) \mathrm{TEC}_{\mathrm{i}}$ ) teve sinal positivo, no entanto, não apresentou significância estatística, potencialmente por esses segmentos serem mais intensivos em capital do que em mão de obra, não gerando uma massa de empregos como os obtidos nas indústrias de baixa e média baixa tecnologia. 
Por fim, a defasagem espacial do emprego industrial de 2014 ( $\rho$ ) apresentou-se importante no processo de formação de postos de trabalho ao longo do estado, de modo que um município que apresente um elevado nível de emprego industrial tende a gerar externalidades aos seus vizinhos, melhorando positivamente o nível de empregos da indústria do seu envoltório. Esse resultado retrata exatamente aquele efeito descrito por Hirschman (1961) acerca do transbordamento dos efeitos aglomerativos, dinamizando o envoltório, contribuindo para o desenvolvimento industrial de toda a região.

Tabela 1 - Diagnósticos para dependência espacial, resultados e testes econométricos dos modelos estimados para o emprego industrial em 2014 e para a variação do emprego industrial 2010-2014 - municípios do Paraná

\begin{tabular}{|c|c|c|c|c|c|c|}
\hline \multirow{2}{*}{$\begin{array}{l}\text { Variáveis } \\
\text { explicativas }\end{array}$} & \multicolumn{3}{|c|}{$\begin{array}{l}\text { Dependente: Emprego industrial } \\
2014 \\
\end{array}$} & \multicolumn{3}{|c|}{$\begin{array}{l}\text { Dependente: Variação emprego industrial } \\
\text { 2010-2014 }\end{array}$} \\
\hline & MQO (1) & SAR (2) & SEM (3) & MQO (4) & SAR (5) & SEM (6) \\
\hline Constante & $\begin{array}{l}70,69 \\
(0,03)^{*}\end{array}$ & $\begin{array}{l}41,34 \\
(0,21)\end{array}$ & $\begin{array}{l}69,90 \\
(0,00)^{*}\end{array}$ & $\begin{array}{l}68,62 \\
(0,00)^{*}\end{array}$ & $\begin{array}{l}54,62 \\
(0,00)^{*}\end{array}$ & $\begin{array}{l}65,49 \\
(0,00)^{*}\end{array}$ \\
\hline $\mathrm{EMP}_{\mathrm{i}}^{(00 / 10)}$ & $\begin{array}{c}1,15 \\
(0,00)^{*}\end{array}$ & $\begin{array}{c}1,15 \\
(0,00)^{*}\end{array}$ & $\begin{array}{c}1,15 \\
(0,00)^{*}\end{array}$ & $\begin{array}{l}-0,03 \\
(0,00)^{*}\end{array}$ & $\begin{array}{c}-0,03 \\
(0,00)^{*}\end{array}$ & $\begin{array}{l}-0,03 \\
(0,00)^{*}\end{array}$ \\
\hline $\mathrm{PRC}_{\mathrm{i}}$ & $\begin{array}{l}734,23 \\
(0,00)^{*}\end{array}$ & $\begin{array}{l}688,43 \\
(0,00)^{*}\end{array}$ & $\begin{array}{l}746,01 \\
(0,00)^{*}\end{array}$ & $\begin{array}{l}538,40 \\
(0,00)^{*}\end{array}$ & $\begin{array}{l}549,67 \\
(0,00)^{*}\end{array}$ & $\begin{array}{l}548,01 \\
(0,00)^{*}\end{array}$ \\
\hline $\mathrm{TEC}_{\mathrm{i}}$ & $\begin{array}{l}139,39 \\
(0,33)\end{array}$ & $\begin{array}{c}152,44 \\
(0,43)\end{array}$ & $\begin{array}{l}124,47 \\
(0,51)\end{array}$ & $\begin{array}{c}-179,81 \\
(0,10)\end{array}$ & $\begin{array}{c}-179,71 \\
(0,11)\end{array}$ & $\begin{array}{c}-179,87 \\
(0,21)\end{array}$ \\
\hline$\rho$ & - & $\begin{array}{c}0,022 \\
(0,03)^{*}\end{array}$ & - & - & $\begin{array}{c}0,10 \\
(0,80)\end{array}$ & - \\
\hline$\lambda$ & - & - & $\begin{array}{c}0,156 \\
(0,05)^{\star}\end{array}$ & - & - & $\begin{array}{c}0,17 \\
(0,02)^{*}\end{array}$ \\
\hline ML lag & $12,74^{*}$ & - & - & $3,89^{*}$ & - & - \\
\hline $\begin{array}{l}\text { ML lag } \\
\text { robust }\end{array}$ & $11,57^{\star}$ & - & - & 0,09 & - & - \\
\hline Ml erro & $4,36^{*}$ & - & - & $6,83^{*}$ & - & - \\
\hline $\begin{array}{l}\text { ML erro } \\
\text { robust }\end{array}$ & $3,18^{\star *}$ & - & - & $3,79^{*}$ & - & - \\
\hline Jarque-bera & $184^{*}$ & - & - & $137^{*}$ & - & - \\
\hline $\begin{array}{l}\text { Breusch- } \\
\text { Pagan }\end{array}$ & $464^{*}$ & - & - & $318^{*}$ & - & - \\
\hline
\end{tabular}

Fonte: Elaborada pelos autores.

Nota: Entre parênteses refere-se ao p-valor da estatística t; * significativa a um nível de significância de $5 \%$. 
A INDÚSTRIA PARANAENSE E O PROGRAMA PARANA COMPETITIVO:

descentralização e o desenvolvimento do setor

Ainda com relação aos dados reportados na Tabela 1 , na sequência (regressões 4, 5 e 6) testou-se o efeito do Programa Paraná Competitivo na variação do emprego industrial, ressaltando que o modelo mais apropriado foi o modelo SEM. Com efeito, os resultados demonstram que a presença de investimentos do Programa Paraná Competitivo tende a elevar, na média, os postos de trabalho da indústria. Ou seja, o Paraná Competitivo não apenas interfere na determinação dos aglomerados de empregos industriais como também na fomentação desses postos de trabalho ao longo do tempo.

Ademais, a dependência espacial da estimativa (6) se manifesta no termo de erro, de modo que os efeitos sobre a variável dependente não advêm apenas do choque (representado pelo termo erro) de uma região, mas do transbordamento de choques oriundos de outras regiões vizinhas. Portanto, outros fatores que conduzam a elevação do emprego em um município impactam positivamente na geração de emprego da região do envoltório.

Por fim, a proxy Path Dependence industrial apareceu com o sinal negativo e estatisticamente significativo. Esse resultado demonstra uma dinâmica de criação do emprego industrial mais intensa naqueles municípios que inicialmente apresentaram uma média de emprego pequena, reforçando a tendência de descentralização do emprego ao longo do Paraná.

Conforme defendem alguns autores, como Saboia e Kubrusly (2008), a ocorrência dessa descentralização pode provocar um incremento da produtividade industrial. A hipótese é de que naquelas regiões receptoras de novas atividades produtivas, em princípio mais moderna que as existentes a priori, se tenha ganhos de produtividade. Ademais, o aumento da demanda por mão de obra também pode impactar nos salários locais. E esses efeitos podem transcender os limites territoriais, beneficiando as regiões vizinhas, por meio da absorção de mão de obra, da compra de matérias-primas, bem como via à instalação de empresas satélites neste envoltório. Enfim, a descentralização da indústria em alguns pontos no espaço pode afetar diretamente o nível de desenvolvimento da indústria, bem como toda a dinâmica regional.

Como no Paraná existe essa tendência de descentralização, analisou-se o desenvolvimento da produtividade indústria, por meio do IDI. No Gráfico 2 apresenta-se a evolução do IDI, separando os municípios que receberam recursos do Programa Paraná Competiti- 
vo ( $\operatorname{Pr}$ competitivo) dos demais municípios do estado e dos outros municípios brasileiros.

Aqueles municípios que receberam investimentos do Paraná Competitivo apresentaram um IDI médio superior durante todos os anos analisados. Ao mesmo tempo, o seu crescimento médio anual também superior $(1,82 \%$ a.a. contra $1,45 \%$ a.a. para os demais municípios do Paraná). Ou seja, a produtividade da indústria paranaense vem sendo ampliada ao longo dos anos, com destaque especial para aqueles municípios participantes do Paraná Competitivo.

Gráfico 2 - Média do IDI - Municípios que receberam investimento do Paraná Competitivo (Pr competitivo), Paraná e Brasil - 2010 a 2014

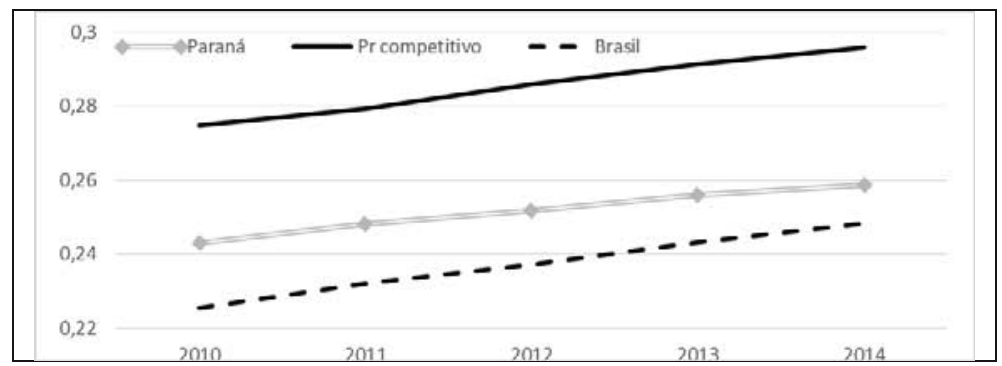

Fonte: Elaborada pelos autores.

Esse avanço pode ser percebido por meio da Figura 2, em que $82 \%$ dos municípios paranaenses melhoraram seu IDI entre 2010 e 2014, elevando os espaços com os melhores resultados. Tal resultado é ratificado por meio da estatística I de Moran, a qual não apresentou significância estatística em 2010, inferindo que a distribuição do IDI no Estado do Paraná é aleatória. Já em 2014, a estatística I de Moran foi positiva e significativa, indicando uma autocorrelação positiva na distribuição da variável IDI; em outras palavras, isso mostra que municípios com elevados (baixos) IDI tendem a estar cercados por municípios com altos (baixos) IDI.

No que tange ao Programa Paraná Competitivo, ao comparar a Figura 2c com a Figura 2d, espacialmente se percebe certa proximidade entre as maiores taxas de crescimento do IDI e os municípios que receberam recursos do Programa. Os resultados da Tabela 2 também corroboram essa percepção, em que, através do I de Moran bivariado pode-se inferir que aqueles municípios que receberam investimentos do Programa Paraná Competitivo tenderam a estar 
A INDÚSTRIA PARANAENSE E O PROGRAMA PARANÁ COMPETITIVO:

descentralização e o desenvolvimento do setor

espacialmente rodeados por municípios com elevados IDI (e vice-versa).

Portanto, é possível que o Programa Paraná Competitivo esteja contribuindo não só para o processo de descentralização do emprego industrial, mas também para elevar o nível de desenvolvimento da indústria ao longo do Estado.

Figura 2 - Índice de Desenvolvimento Industrial em 2010 (a), em 2014

(b), taxa de crescimento do IDI entre 2010 e 2014 (c) e Investimentos do Paraná Competitivo entre 2011 e 2014 (d) - municípios do Paraná

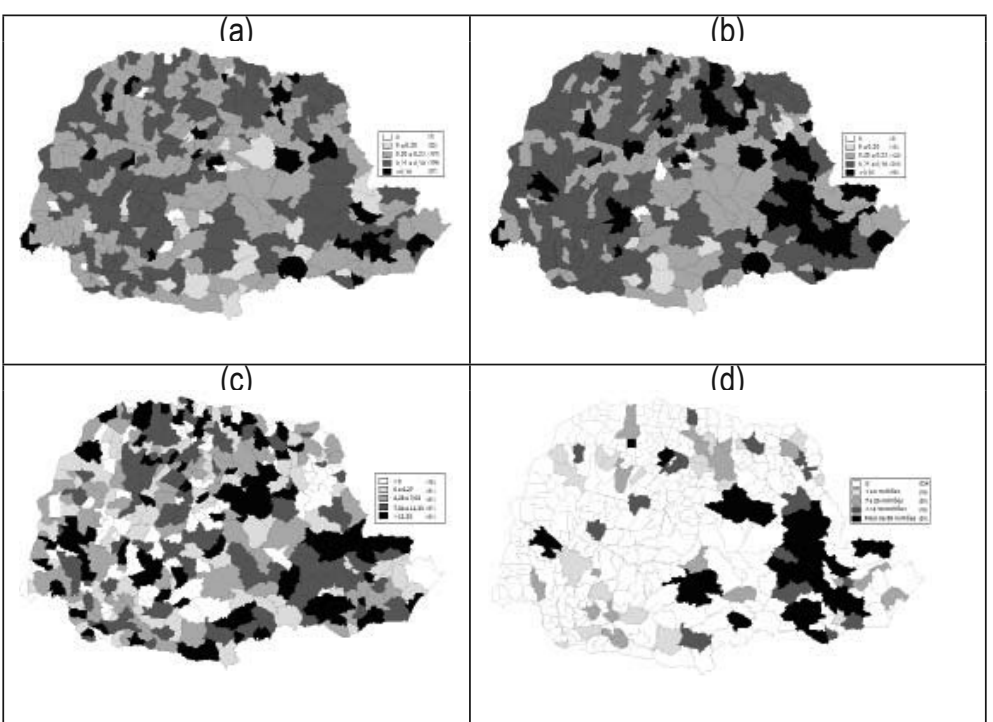

Fonte: Organizado pelos autores, com os dados da pesquisa, por meio do software Geoda.

Tabela 2 - Coeficiente I de Moran para o IDI e I de Moran bivariado entre IDI e investimentos do Programa Paraná competitivo (IPr Comp.) - municípios do Paraná

\begin{tabular}{l|c|c|c|c}
\hline & \multicolumn{4}{|c}{ Convenção } \\
\hline & Rainha & Torre & 4 Vizinhos & 5 vizinhos \\
\hline IDI 2010 & 0,04 & 0,04 & 0,05 & 0,04 \\
IDI 2014 & $0,10^{*}$ & $0,10^{*}$ & $0,13^{*}$ & $0,12^{*}$ \\
Bivariado - IDI 2014 e IPr Comp. & $0,06^{*}$ & $0,06^{*}$ & $0,08^{*}$ & $0,08^{*}$ \\
\hline
\end{tabular}

Fonte: Elaborada pelos autores, com os dados da pesquisa, por meio do software Geoda.

Nota: A pseudo-significância empírica baseada em 999 permutações aleatórias; * significativo a um nível de significância de $5 \%$. 
Augusta Pelinski Raiher | Alex Sander Souza do Carmo

Hermes Yukio Higachi | Jorge Eduardo Wekerlin

Visando testar o efeito do Programa Paraná Competitivo no desenvolvimento industrial do Estado do Paraná tem-se as estimativas apresentadas na Tabela 3, ressaltando que o modelo mais apropriado é o SAR.

O que se constata é a efetividade do Programa no melhoramento da produtividade industrial, de maneira que naqueles municípios que tiveram investimentos do Paraná Competitivo teve-se, na média, um nível de produtividade mais elevado. E compreensível tal resultado tendo em vista que a ação direta do Programa foi em atrair novas empresas e/ou ampliar a capacidade produtiva já instalada, dinamização da atividade produtiva, afetando, consequentemente, a produtividade da indústria local.

Ademais, constatou-se que a existência de Path Dependence é importante no processo de desenvolvimento da indústria, impactando positivamente o IDI. Quanto maior é o aglomerado de empregos inicial, maior tende a ser o IDI subsequente, de modo que se uma região elevar a dinâmica de seu parque produtivo, amplia a possibilidade de ter um maior desenvolvimento da indústria no tempo seguinte.

Além da importância da trajetória industrial, constatou-se que o padrão de especialização da atividade produtiva é importante na determinação da produtividade da indústria. Com efeito, naqueles municípios em que a estrutura produtiva está ancorada principalmente na produção de bens de alta e média alta tecnologia, a produtividade da indústria se apresentou, na média, superior aos demais municípios. Portanto, a composição da estrutura produtiva é um elemento importante neste processo ${ }^{4}$.

Por fim, existem ganhos de externalidades, de maneira que se um município auferir um maior desenvolvimento da indústria, os seus vizinhos também são beneficiados. O coeficiente positivo e significativo da defasagem espacial da variável dependente demonstra um transbordamento positivo do IDI na dinâmica do desenvolvimento industrial do envoltório. Isto mostra que, quando determinada região melhora a produtividade da sua indústria, parte desse desenvolvimento também acaba beneficiando as regiões do envoltório, criando um ciclo virtuoso para atividade produtiva. 
A INDÚSTRIA PARANAENSE E O PROGRAMA PARANÁ COMPETITIVO: descentralização e o desenvolvimento do setor

Tabela 3 - Diagnósticos para dependência espacial, resultados e testes econométricos dos modelos estimados para IDI em 2014 - municípios do Paraná

\begin{tabular}{lcccc}
\hline & MQO & SAR & SEM \\
\hline Constante & 0,257 & 0,14 & 0,26 \\
& $(0,00)^{*}$ & $(0,00)^{*}$ & $(0,00)^{*}$ \\
EMP $_{\mathrm{i}}^{(00 / 10)}$ & 0,000001 & 0,000001 & 0,000001 \\
$\mathrm{PRC}_{\mathrm{i}}$ & $(0,00)^{*}$ & $(0,00)^{*}$ & $(0,00)^{*}$ \\
& 0,03 & 0,027 & 0,029 \\
$\mathrm{TEC}_{\mathrm{i}}$ & $(0,00)^{*}$ & $(0,00)^{*}$ & $(0,00)^{*}$ \\
& 0,019 & 0,017 & 0,017 \\
& $(0,06)^{* *}$ & $(0,09)^{* *}$ & $(0,00)^{*}$ \\
\multicolumn{1}{c}{$\boldsymbol{\lambda}$} & - & 0,43 & - \\
& & $(0,00)^{*}$ & - \\
ML lag & - & - & 0,16 \\
ML lag robust & & - & $(0,00)^{*}$ \\
Ml erro & $7,95^{*}$ & - & - \\
ML erro robust & $4,15^{*}$ & - & - \\
Jarque-bera & $5,01^{*}$ & - & - \\
Breusch-Pagan & 1,21 & - & - \\
\hline
\end{tabular}

Fonte: Elaborada pelos autores.

Nota: Entre parênteses refere-se ao p-valor da estatística t; * significativa a um nível de significância de 5\%; ${ }^{* *}$ significativa a um nível de significância de $10 \%$.

\section{CONCLUSÃO}

O objetivo deste trabalho consistiu na análise da descentralização e do desenvolvimento - em termos de produtividade - da indústria paranaense, e a importância do Programa Paraná Competitivo neste processo. Os resultados demonstraram que efetivamente vem ocorrendo um processo de homogeneização do emprego industrial ao longo do estado, resultado de uma tendência nacional, mas também decorrente de políticas internas específicas, como é o caso do Programa Paraná Competitivo.

Tal programa está impactando não apenas na distribuição da indústria ao longo do estado, mas também no desenvolvimento do setor. Isso é extremamente importante no sentido de tornar mais competitiva a indústria paranaense, promovendo um círculo virtuoso de crescimento. Como existe um efeito ex post no desenvolvimento da indústria quando se tem um passado industrial, a distribuição 
desses investimentos ao longo do Paraná se torna importante, não apenas para a geração de emprego e renda no presente, mas para o próprio processo de fomentação futura do setor.

Ademais, os controles espaciais demonstram que os efeitos de emprego e de desenvolvimento da indústria não ficam restritos aos limites do município onde a indústria está instalada, mas ultrapassam essas fronteiras, beneficiando as regiões circunvizinhas. Isso é importante na própria dinâmica de atração dos próximos investimentos, que podem ser alocados estrategicamente para desenvolver o setor naquelas áreas onde a atividade produtiva é carente.

Por fim, percebeu-se um ganho de desenvolvimento daqueles municípios que apresentam aglomerações especializadas na alta e média alta tecnologia. O Paraná detém vantagem comparativa na produção de bens menos intensos em tecnologia por apresentar uma elevada competitividade do seu setor primário, acarretando, consequentemente, numa competitividade superior dos bens derivados desse setor. No entanto, é necessário avançar nestes outros segmentos da indústria, com maior intensidade tecnológica, os quais agregam maior valor aos bens, detendo uma elasticidade-renda da demanda mais elevada. Portanto, é necessário pensar, dentro da política industrial do estado, como desenvolver tais segmentos e como incentivar a vida de empresas desses ramos industriais.

\section{REFERÊNCIAS}

ALMEIDA, E. Econometria Espacial Aplicada. Campinas, SP: Editora Alínea, 2012.

BRAGUETO, C. R. O aglomerado urbano-industrial de Londrina: sua constituição e dinâmica industrial. 2007. 249f. Tese (Doutorado em Geografia Humana) - Faculdade de Filosofia, Letras e Ciências Humanas, Universidade de São Paulo, São Paulo, 2007.

BRASIL. Ministério do Trabalho. Relação Anual de Informações Sociais: acesso ao sistema. Brasília, DF, [20--?]. Disponível em: $<$ http://bi.mte.gov.br/bgcaged/login.php>. Acesso: 1 maio 2016.

CROCCO, M. A. et al. Metodologia de identificação de aglomerações produtivas locais, Nova Economia, Belo Horizonte, v.16, p. 211-241, maio/ago. 2006.

FURTADO, A. T.; CARVALHO, R. Q. Padrões de intensidade tecnológica da indústria brasileira: um estudo comparativo com os 
A INDÚSTRIA PARANAENSE E O PROGRAMA PARANA COMPETITIVO:

descentralização e o desenvolvimento do setor

países centrais. São Paulo em Perspectiva, São Paulo, v. 19, n.1, p. 70-84, jan./mar. 2005.

HIRSCHMAN, A. Estratégia do desenvolvimento econômico. Rio de Janeiro: Ed. Fundo de Cultura, 1961.

INSTITUTO BRASILEIRO DE GEOGRAFIA E ESTATÍSTICA.

Contas Regionais. Rio de Janeiro, 2014. Disponível em: $<$ http://

downloads.ibge.gov.br/downloads_estatisticas.htm>. Acesso em:1 dez. 2016.

INSTITUTO DE PESQUISA ECONÔMICA APLICADA.

IPEADATA: Regional. Rio de Janeiro, [20--?]. Disponível em: $<$ http// ipeadata.gov.br>. Acesso em: 1 dez. 2016.

INSTITUTO PARANAENSE DE DESENVOLVIMENTO

ECONÔMICO E SOCIAL. Paraná: diagnóstico social e econômico. Curitiba, 2003.

KRUGMAN, P. R. Geography and Trade. Cambridge: MIT Press, 1991.

MARSHALL, A. Principles of Economics. London: Macmillan, 1890.

SABOIA, J. Aglomerações industriais especializadas no Brasil.

Rio de Janeiro, 2000. NT no 45/00, projeto Arranjos e Sistemas

Produtivos Locais e as Novas Políticas de Desenvolvimento Industrial e tecnológico, GEI/IE/UFRJ.

; KUBRUSLY, L. S. Diferenciais Regionais e Setoriais na Indústria Brasileira. Revista de Economia Aplicada, Ribeirão Preto, v. 12, n. 1, p. 125-149, jan./mar. 2008.

SCHMITZ, H. Eficiência coletiva: caminho de crescimento para a indústria de pequeno porte. Ensaios FEE, Porto Alegre, v. 18, n. 2, p. 164-200, 1997.

SCITOVSKY, T. Two Concepts of External Economies. Journal of Political Economy, Chicago, v. 62, n. 2, p. 143-151, apr. 1954.

\section{NOTAS}

1 Este artigo faz parte do projeto financiado com recursos da Secretaria de Estado da Ciência Tecnologia, e Ensino Superior (Seti) - Fundo Paraná: Avaliação da Efetividade e do Efeito Econômico e Social do Programa Paraná Competitivo do Estado do Paraná.

2 Deflacionado pelo Índice Nacional de Preço ao Consumidor (INPC).

3 Conforme os resultados do APÊNDICE A, a convenção mais indicada nestas estimativas refere-se à matriz 5 vizinhos.

4 Cabe destacar que outras estimativas foram feitas, considerando uma participação do emprego da alta e média alta tecnologia igual ou superior a $25 \%$, e os resultados se 
Augusta Pelinski Raiher | Alex Sander Souza do Carmo

Hermes Yukio Higachi | Jorge Eduardo Wekerlin

mantiveram iguais: nenhum efeito estatisticamente significativo para a determinação do nível de emprego industrial de 2014 e nenhum efeito na variação do emprego entre 2010 e 2014; e um efeito positivo e significativo na determinação do IDI de 2014.

\section{APÊNDICES}

APÊNDICE A - I de Moran para determinar a melhor convenção para as estimativas (Tabela 1 e 3 ) e para os resíduos resultantes

\begin{tabular}{lccccc}
\hline & Rainha & Torre & 4 vizinhos & 5 vizinhos \\
\hline I de Moran - regressão tabela 3 (IDI 2014) & 1,28 & 1,26 & $2,10^{*}$ & $2,20^{\star}$ \\
I de Moran - regressão tabela 1 (variação do & $1,67^{\star}$ & $1,63^{\star}$ & $2,51^{*}$ & $2,54^{\star}$ \\
emprego2010/2014) & & & & \\
I de Moran - regressão tabela 3(emprego 2014) & 1,42 & 1,44 & $2,10^{*}$ & $2,18^{\star}$ \\
I de Moran resíduo - tabela 3 (IDI 2014) & $-0,02$ & $-0,01$ & $-0,002$ & $-0,001$ \\
I de Moran resíduo - tabela 1 (variação do & 0,05 & 0,055 & 0,007 & 0,06 \\
emprego2010/2014) & & & & \\
I de Moran resíduo - tabela 1 (emprego 2014) & 0,05 & 0,049 & 0,008 & 0,006 \\
\hline
\end{tabular}

Fonte: Elaborada pelos autores.

Nota: * significativo a um nível de significância de 5\%. A pseudo-significância empírica baseada em 999 permutações aleatórias.

APÊNDICE B - Pesos utilizados na construção do IDI

\begin{tabular}{|l|c|c|c|}
\hline & ESC & SAL & OT \\
\hline Pesos & 0,335 & 0,34 & 0,325 \\
\hline
\end{tabular}

Fonte: Elaborada pelos autores. 